Check for updates

Cite this: RSC Adv., 2019, 9, 29463

\title{
Microgrooved collagen-based corneal scaffold for promoting collective cell migration and antifibrosis
}

\author{
Sijia Xiong, ${ }^{\text {abc }}$ Huichang Gao, ${ }^{* d}$ Lanfeng Qin, ${ }^{\text {bce }}$ Yongguang Jia, (D) ab Meng Gao (D) ab \\ and Li Ren (D)*abf
}

Collagen is a promising material for corneal tissue engineering. The surface topography of collagen is critical for cornea reconstruction and regeneration. Herein, we fabricated collagen films with microgrooved surface to investigate the effect of collagen film topography on corneal cell migration and antifibrosis. We found that the patterned films with microscale grooves could greatly affect the orientation, proliferation, migration, and gene expression of rabbit corneal epithelial cells and keratocytes. Compared with the natural cornea, the optimized collagen films with microgroove pattern show similar swelling performance, optical clarity, and biodegradability, which could efficiently promote the epithelial cell migration, accelerate wound healing process, and inhibit the fibrosis of keratocytes. These results suggest that collagen films with microgroove pattern are promising in corneal tissue engineering.

Received 27th May 2019

Accepted 19th July 2019

DOI: 10.1039/c9ra04009a

rsc.li/rsc-advances

transformation of keratocytes. ${ }^{13,14}$ In addition, a slow migration rate of corneal epithelial cells may also inhibit the regeneration of corneal epithelial tissue. Therefore, it's critical to develop cornea substitutes which can inhibit keratocyte differentiation and accelerate corneal epithelial cell migration.

The basement membrane between the cornea epithelium and stroma has been found to have macro- and nanoscale topography features, providing unique sites for cell-substrate interactions. ${ }^{15-17}$ In addition, the corneal stroma has highlyorganized structure with aligned collagen fibers and cells, which determines cornea's transparency. ${ }^{18}$ Therefore, it's important to introduce topographic cues into corneal tissue engineering for mimicking the microenvironment of cells. Previous studies have shown that the engineering substrate topography can significantly influence cell shape, ${ }^{19,20}$ adhesion, ${ }^{21-23}$ migration, ${ }^{24}$ proliferation, ${ }^{25-27}$ and differentiation. ${ }^{28,29}$ For corneal cells, their behaviors are also regulated by surface topography ${ }^{30,31}$ For example, the extracellular matrix expression of keratocytes could be regulated to recreate the structure of the stroma. ${ }^{32,33}$ In addition, some studies have broached that patterned surfaces can promote the migration of corneal epithelial cells. ${ }^{34,35}$ Therefore, the topography-cell interaction could be combined with corneal tissue engineering to develop a micropatterned scaffold that is able to regulate cells. Such strategy may reduce keratocyte differentiation and accelerate corneal epithelial cell migration, which not only helps regulate corneal cell behavior but also mimic the in vivo microenvironment of the native cornea. ${ }^{36} \mathrm{In}$ this work, collagen was chosen as a scaffold material, and engineering microscale groove structure was applied to fabricated a corneal tissue engineering scaffold, aiming to accelerate corneal epithelial cell migration and reduce keratocyte differentiation (Fig. 1). The influences of

\author{
Guangzhou 510641, China. E-mail: psliren@scut.edu.cn \\ ${ }^{b}$ National Engineering Research Centre for Tissue Restoration and Reconstruction, \\ Guangzhou 510006, China \\ University of Technology, Guangzhou 510006, China \\ ${ }^{d}$ School of Medicine, South China University of Technology, Guangzhou 510006, China \\ eSchool of Biology and Biological Engineering, South China University of Technology, \\ Guangzhou 510006, China. E-mail: mchcgao@scut.edu.cn \\ ${ }^{f}$ Sino-Singapore International Joint Research Institute, Guangzhou 510555, China
}


surface topography on swelling capacity, optical clarity, and degradation rate of collagen films were studied. Also, response of rabbit corneal epithelial cells (CECs) and keratocytes, including orientation, proliferation, migration, and differentiation, on the micropatterned surface were observed. Overall, the study offers an insight into cell-topography interaction and the use of surface topography for corneal issue engineering.

\section{Experimental}

\section{Materials}

Type I collagen was extracted from bovine tendon. 1-(3Dimethylaminopropyl)-3-ethylcarbodiimide hydrochloride (EDC) and $N$-hydroxysuccinimide (NHS) were supplied by Sigma-Aldrich Corporation (Germany). Hydrochloric acid ( $\mathrm{HCl}$ ), acetone and isopropanol were obtained from Guanghua Chemical Factory (China). Deionized water was prepared by the water purification system (Millipore S. A. S, France). NR2120000P negative photoresist was provided by Futurrex company (USA). The poly(dimethylsiloxane) prepolymer, sylgard 184, was purchased from Dow Corning (USA). Collagenase type I was provided from Solarbio company (China). Phosphate buffered saline (PBS, pH = 7.4), Dulbecco's modified Eagle medium (DMEM), fetal bovine serum (FBS) and other cellculture related reagents were all bought from Gibco (USA). Cell Counting Kit-8 (CCK-8) was provided from Dojindo Laboratories (Japan). F-Actin Labeling Kit and 4',6-diamidino-2phenylindole (DAPI) were both from AAT (USA). Recombinant human TGF- $\beta 1$ was provided by PeproTech (USA). HiPure Total RNA Micro Kit was purchased from Magen (China), and reverse transcription reagents kit from Takara (Japan). BCA Protein Assay Kit was bought from Beyotime (China). The rabbit corneal epithelial cells (CECs) and keratocytes were provided by Rochen Pharma (China).

\section{PDMS template preparation}

A method combining soft lithography with solution casting were used to fabricate microgrooved collagen films. Fig. 2 showed the main steps. Firstly, soft lithography was employed to prepare a poly(dimethylsiloxane) (PDMS) template (Fig. 2a). In brief, the patterned silicon wafer was fabricated using traditional photolithography techniques. Groove patterns with different groove width $(25 \mu \mathrm{m}, 50 \mu \mathrm{m}, 100 \mu \mathrm{m})$, same ridge width $(200 \mu \mathrm{m})$, and depth $(50 \mu \mathrm{m})$ was designed using Computer Aided Design (Autodesk Inc.) to product a mask. Then flat silicon wafers coated with negative photoresist was baked at $80{ }^{\circ} \mathrm{C}$ for $10 \mathrm{~min}$ and $150{ }^{\circ} \mathrm{C}$ for $5 \mathrm{~min}$. Then the photoresist was exposed to UV light through the mask, and the silicon wafers with expected patterns were produced after development in RD6 developer solution. Subsequently, a mixture of PDMS prepolymer and curing agent $(10: 1 \mathrm{w} / \mathrm{w})$ was poured onto the silicon wafer and cured at $60{ }^{\circ} \mathrm{C}$ for $4 \mathrm{~h}$, and a PDMS template was obtained.

\section{Micropatterned film fabrication}

The microgrooved collagen film was fabricated with the method of solvent casting (Fig. 2b). Briefly, collagen solution was prepared by dissolving type I collagen in $0.01 \mathrm{M} \mathrm{HCl}$ solution at $4{ }^{\circ} \mathrm{C}$. Then cross-linking agent EDC and the catalyst NHS were added to the collagen solution according to a mass ratio of EDC : NHS : collagen $=1: 1: 6$, and the mixture was stirred by an electromagnetic stirrer (SP-18, MIULAB, China) at $4{ }^{\circ} \mathrm{C}$ to thoroughly mix and cross-link. Next, the mixture was casted onto a container, the bottom of which was covered by the micropatterned PDMS template. After air dried, the collagen films were peeled off from the template, and micropatterned films were obtained. Unpatterned film was prepared with the same method, expect that the PDMS template was unpatterned. The morphology of microgrooved collagen films was observed.
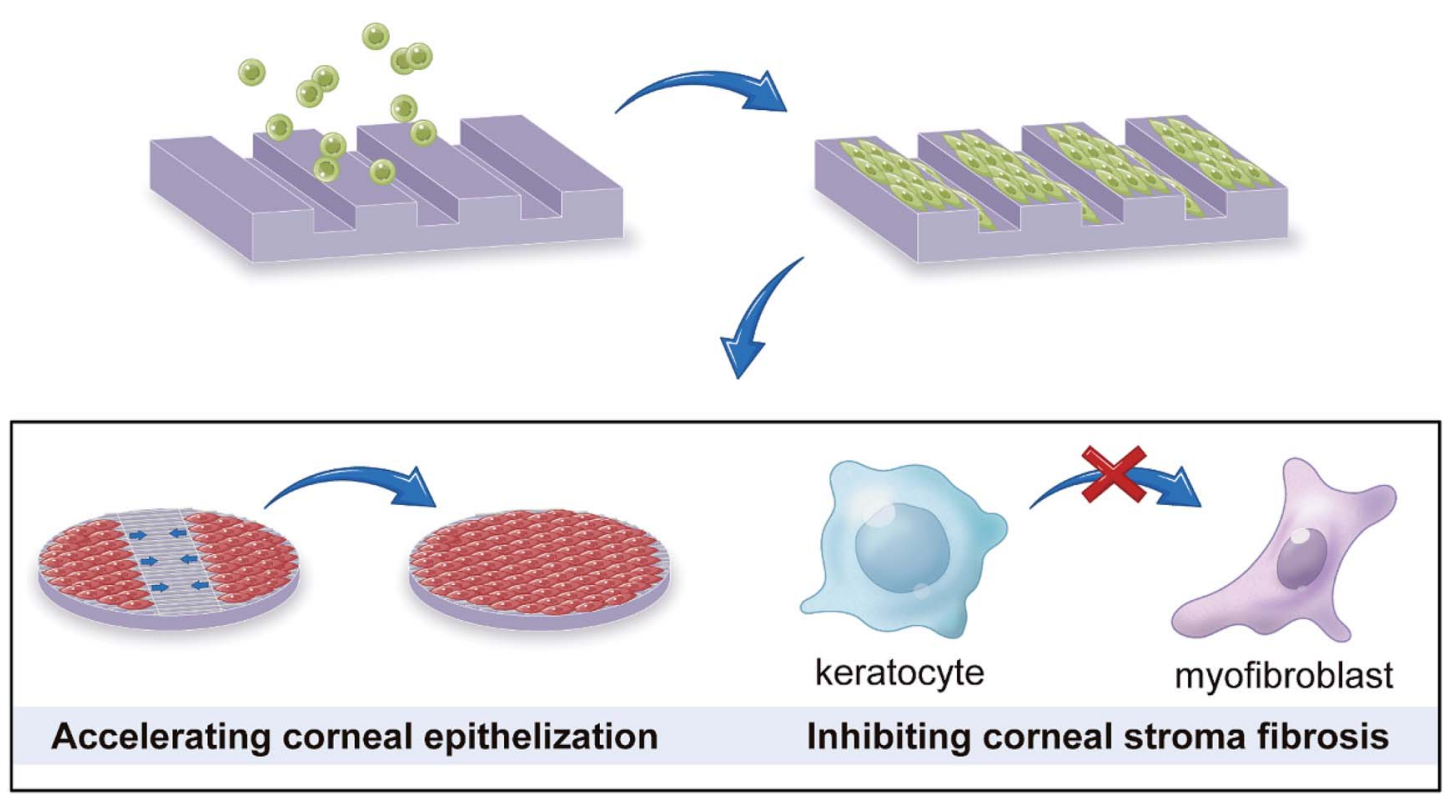

Fig. 1 Microgrooved collagen films was fabricated to explore its application potential for corneal tissue engineering. 
(a) PDMS template preparation

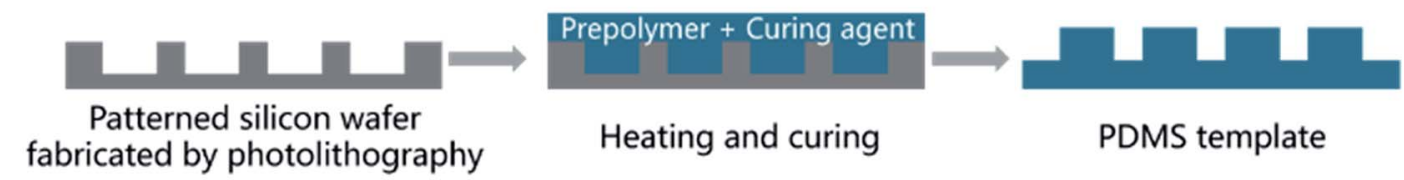

(b) Micropatterned collagen film fabrication

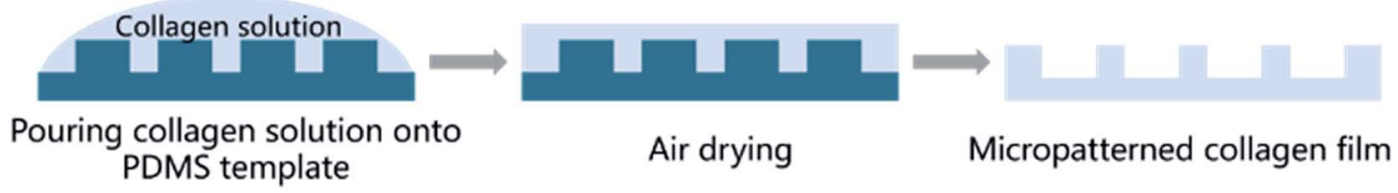

Fig. 2 Schematic illustration of patterned collagen film fabrication process shows the two main steps: preparation of PDMS and fabrication of micropatterned collagen films.

\section{Swelling test}

To characterize water absorption ability of micropatterned collagen films, swelling test was conducted. In brief, dry collagen films were weighed and then immersed in PBS $(\mathrm{pH}=7.4)$. At regular time intervals, swollen collagen films were taken out and blotted with filter paper to remove the superficial water, and subsequently the weight of the collagen films were measured. The water absorption of films is computed from the following equation:

$$
\text { Water absorption }=\left(M_{t}-M_{0}\right) / M_{t} \times 100 \%
$$

where $M_{t}$ and $M_{0}$ are weight of films at specified time and initial weight of dry films, respectively.

\section{Light transmittance}

In order to study optical performance of micropatterned collagen films, the light transmittance of the films was measured using an ultraviolet-visible spectro-photometer (Shanghai UNICO, China). Briefly, collagen films were immersed in PBS solution $(\mathrm{pH}=7.4)$ to water equilibrium and then scanned in the range of $400-700 \mathrm{~nm}$ at room temperature.

\section{In vitro degradation}

In vitro degradation test was performed to evaluate the degradation rate of films. In brief, after weighed, collagen films fully equilibrated with water were placed in $5 \mathrm{ml}$ PBS which contains collagenase type I $\left(5 \mathrm{U} \mathrm{ml}^{-1}\right)$. Then, the system was incubated at $37^{\circ} \mathrm{C}$ and the weight of films was recorded with time until films degraded completely. The residual mass of films was normalized according the following formula,

$$
\text { Residual mass }(\%)=W_{t} / W_{0} \times 100 \%
$$

where $W_{t}$ is the weight of films at specified time and $W_{0}$ is the initial weight of films.

\section{Cell culture and seeding}

CECs and keratocytes were cultured in DMEM medium supplemented with $10 \%$ FBS. All the cells were kept at $5 \% \mathrm{CO}_{2}$,
$37{ }^{\circ} \mathrm{C}$. After sterilized by ultraviolet radiation, collagen films were placed in 24-well plates and fixed with sterilized rubber rings. Then, collagen films were rinsed by PBS for three times to remove residual hydrochloric acid. Finally, cells were seeded onto the collagen films and cultured for a set period of time, with medium replaced every $48 \mathrm{~h}$.

\section{Cell proliferation assay}

CCK-8 was used to assess the proliferation of the CECs and keratocytes on micropatterned collagen films with different groove width. In brief, CECs and keratocytes were seeded onto the surface of collagen films at densities of $1.0 \times 10^{4}$ cells per well. At the prescribed time points $(1,3,5 \mathrm{~d})$, CCK- 8 working solution was added to each well and incubated for $1 \mathrm{~h}$ at $37^{\circ} \mathrm{C}$. Subsequently, the supernatant medium was extracted, and its absorbance at $450 \mathrm{~nm}$ was measured by a microplate reader (Thermo 3001, Thermo, America) $(n=5)$.

\section{Florescent staining}

The morphology and orientation of cells cultured on microgrooved collagen films were studied by florescent staining. In brief, after culture medium removed, cells were washed with PBS, then fixed in 4\% paraformaldehyde solution for $15 \mathrm{~min}$ at room temperature and subsequently washed with PBS. Next, the cells were permeabilized with $0.1 \%$ Triton-X 100 for $15 \mathrm{~min}$ and then washed with PBS again. Thereafter, the cells were immersed in F-actin labelling probe for $1 \mathrm{~h}$ to stain the actin filaments. After rinsed with PBS for $5 \mathrm{~min}$, DAPI was added to the culture plate for $15 \mathrm{~min}$ with two subsequent PBS rinses ( 5 min per wash). Finally, the morphology of fluorescently stained cells on the micropatterned substrates was observed by a confocal laser scanning microscopy (SP8, Leica, Germany).

\section{In vitro would healing assay}

To assess the effects of patterned surface on the migration activities of CECs, an in vitro would healing assay was conducted. Briefly, $1 \mathrm{~mm}$-wide titanium strips were placed perpendicularly with axis of grooves onto each film and fixed by rubber rings. The CECs were seeded onto microgrooved 
collagen films at a density of $5.0 \times 10^{4}$ cells per well. After cells were cultured for 24 hours, the titanium strip was taken out and a $1 \mathrm{~mm}$-wide wound gap was generated. The images of wound gaps on 0,24 and $48 \mathrm{~h}$ were captured using a confocal laser scanning microscopy. Before observation, the cells were incubated with a self-made fluorescent cytoplasm staining dye (a kind of aggregation-induced emission molecule) for $1 \mathrm{~h}$.

\section{Cell differentiation}

The myofibroblast transformation of keratocytes was explored by real-time polymerase chain reaction (RT-PCR). In brief, keratocytes were seeded onto collagen films and cultured for 3 days. Then $2.5 \mathrm{ng} \mathrm{ml} \mathrm{m}^{-1}$ recombinant human TGF- $\beta 1$ was added and cells were cultured for another 3 days. Then RNA was extracted using the HiPure Total RNA Micro Kit following the manufacturer's instructions. Total RNA concentrations were quantified using NanoDrop 2000 (Thermo Scientific, USA). Next, a reverse transcription reagents kit was used to synthesize cDNA. Finally, RT-PCR was achieved using the SYBR green system (Genecopoeia, USA). Amplifications for cDNA samples were carried out at $50{ }^{\circ} \mathrm{C}$ for $2 \mathrm{~min}$ and at $95{ }^{\circ} \mathrm{C}$ for $10 \mathrm{~min}$, followed by 40 cycles at $95{ }^{\circ} \mathrm{C}$ for $15 \mathrm{~s}, 60{ }^{\circ} \mathrm{C}$ for $30 \mathrm{~s}$, and $72{ }^{\circ} \mathrm{C}$ for $30 \mathrm{~s}$. The following primer sequences were used: GAPDH: forward: $5^{\prime}$-ACTTCGGCATTGTGGAGG-3' ${ }^{\prime}$; reverse: $5^{\prime}$-GGAGGCAGGGATGATGTTCT-3' for $\alpha$-SMA: forward: $5^{\prime}$-CCATGCCATCATGCGTCT-3'; reverse: $5^{\prime}$ GCCATCTCGTTTTCAAAGTCC-3'; for Col1A1: forward: $5^{\prime}$ GCCTGAGCCAGCAGATTGA-3' ${ }^{\prime}$; reverse: $5^{\prime}$-AGGTTGCCCCAGTGTCCAT-3'; CTGF: forward: $5^{\prime}$-AGGAGTGGGTGTGTGATGAG-3' ${ }^{\prime}$; reverse: $5^{\prime}$-CCAAATGTGTCTTCCAGTCG-3' ${ }^{\prime}$. The relative quantification of target genes was normalized to the corresponding value of glyceraldehyde-3-phosphate dehydrogenase $(\mathrm{GAPDH})$ and calculated using the $2^{-\Delta C_{\mathrm{t}}}$ method.

\section{Western blotting analysis}

Keratocytes cultured on collagen films were collected and lysed in reagent containing RIPA buffer and PBST. After cell lysates were centrifuged at $13000 \mathrm{rpm}$ for $5 \mathrm{~min}$, the supernatant was collected and the protein was quantified with a BCA Protein Assay Kit, followed by mixture with $25 \mu \mathrm{l} 2 \times$ SDS-PAGE loading buffer (100 mM Tris-HCl, pH 6.8, containing $200 \mathrm{mM}$ DTT, $4 \%$ SDS, $0.2 \%$ BPB, $20 \%$ glycerol). After being heated at $95{ }^{\circ} \mathrm{C}$ for $5 \mathrm{~min}$, equal amount of protein samples was loaded onto separation gel and stacking gel (1 M Tris, pH 8.8, containing water, $30 \%$ acrylamide, $10 \%$ SDS, $10 \%$ AP, TEMED). Gel electrophoresis was performed at $60 \mathrm{~V}$ for $25 \mathrm{~min}$ followed by $80 \mathrm{~V}$ for $1 \mathrm{~h}$. The proteins were then transferred onto PVDF membrane. The membrane was blocked with 5\% non-fat milk in PBSF for $45 \mathrm{~min}$ at room temperature and then incubated with a primary antibody for $1 \mathrm{~h}$ in room temperature. Before incubating with a goat anti-rabbit IgG or anti-mouse IgG antibody for $30 \mathrm{~min}$, the membranes were washed with PBSF, protein bands were detected by enhanced chemiluminescence according to the manufacturer's instructions and an imaging system.

\section{Image and statistical analysis}

Images were analysed with ImageJ software. A one-way ANOVA was performed to assess the level of significance. Results are expressed as the mean \pm standard error, and $p<0.05$ was designated as statistically significant.

\section{Results and discussion}

Fabrication and characterization of microgrooved collagen films

In this study, the microgrooved collagen films were successfully fabricated by the method of combining soft lithography techniques and solvent casting. All three of the patterns have the same ridge width $(200 \mu \mathrm{m})$ and groove depth $(50 \mu \mathrm{m})$, and the grooves widths were $25 \mu \mathrm{m}, 50 \mu \mathrm{m}$, and $100 \mu \mathrm{m}$, respectively. In our study, microgroove was chosen as the micropattern for two reasons. First, the groove structure can mimic the highlyorganized structure with aligned collagen fibres for the corneal stroma to a certain degree. Second, the parallel groove topology can guide the directed migration of cells and may be contribute to the epithelialization of corneal epithelial cells. ${ }^{37}$ In addition, microscale grooves have comparable size with cells and can regulate the behaviour of cell populations. ${ }^{38}$ For the sake of convenience, we labelled the three patterned collagen films as W25D50 (groove width: $25 \mu \mathrm{m}$, depth: $50 \mu \mathrm{m}$ ), W50D50 (groove width: $50 \mu \mathrm{m}$, depth: $50 \mu \mathrm{m}$ ) and W100D50 (groove width: $100 \mu \mathrm{m}$, depth: $50 \mu \mathrm{m}$ ). The unpatterned collagen film as control group was labelled as Smooth.

The morphology of acquired collagen films were evaluated by SEM (Fig. 3). As we can see, the as-prepared samples exhibited clean surface without impurity particles, and the microgroove features including shape and size are in good accordance with the design, indicative of the precise pattern transfer between PDMS template and collagen replica. The SEM image demonstrated that expected topography features with high fidelity were successfully produced on the surface of collagen film, which
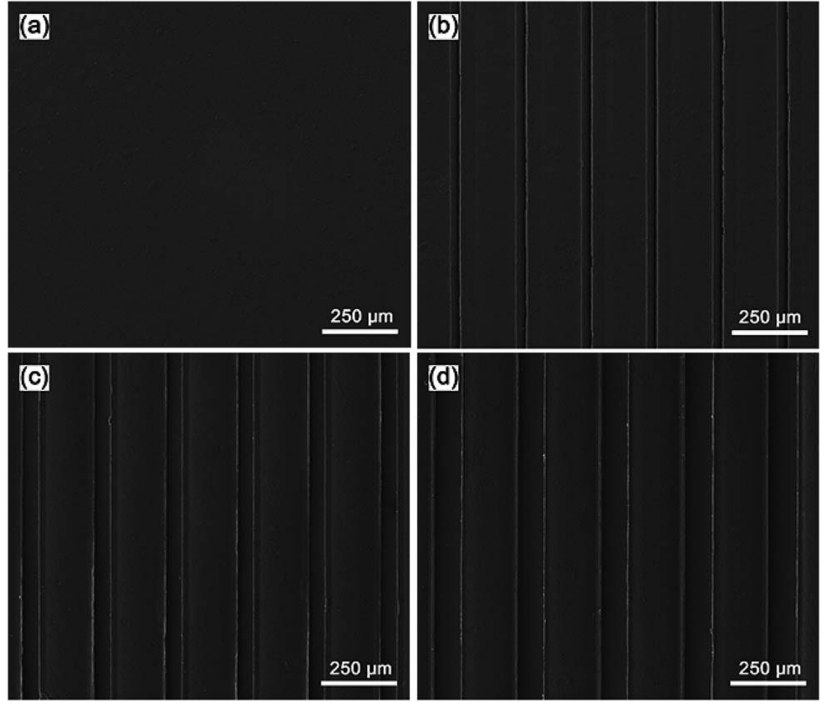

Fig. 3 SEM image of collagen film surface, (a) Smooth, (b) W25D50, (c) W50D50, (d) W100D50. 
means that the fabrication method of patterned collagen films used in this study is robust and can be applied to the production of collagen films with various microgrooves. In addition, compared to other microfabrication methods, the way combining soft lithography and solvent casting is relatively inexpensive and more suitable mass production.

\section{Physicochemical properties of collagen films}

As corneal tissue engineering scaffold, there are a lot of prerequisites must be met for candidate materials, such as transparency, swelling property, degradation rate and so on. ${ }^{5}$ To evaluate the feasibility of microgrooved collagen membrane as corneal tissue engineering scaffold, a series of properties of microgrooved collagen films was determined. Appropriate water content of cornea helps to maintain corneal structure and plays an important role in transparency of the cornea. ${ }^{39}$ The result of swelling test was shown in Fig. 4a. As we can see, the water contents of all four kind of collagen films were about 85\%, which is comparable to the value of healthy human cornea and can meet the demand of tissue engineered cornea. ${ }^{\mathbf{4 0}}$

Besides, there were no significant differences in equilibrium water absorption between patterned collagen films with different groove size and unpatterned collagen films. These results strongly suggested that surface micropatterning had no impact on swelling performance of collagen films. The reason might be that the flat and patterned films have similar internal microstructures and crosslinking density, which determines the property of swelling performance.
One of the most important function of cornea is to transmit incoming light to interior optical element. Therefore, the effect of microgrooves on the transparency of the collagen films was accessed by testing visible light transmission of films. As shown in Fig. $4 \mathrm{~b}$, the light transmission of all the films increased with the increase of the wavelength, which is similar to the human cornea. Collagen films with smooth surface have good optical property with the light transmission reaching $90 \%$ at $800 \mathrm{~nm}$. After micropatterning, there was a slight decrease in transparency of collagen films, which might result from the increased light scattering induced by patterned surface. These patterned films with different groove width showed similar optical performance, and the light transmission is about $70 \%$ at $400 \mathrm{~nm}$, and near $80 \%$ at $750 \mathrm{~nm}$. Compared to human cornea whose visible light transmission is about $90 \%$, the patterned collagen films showed an acceptable decrease in transparency. Therefore, the patterned collagen films could satisfy the request of corneal tissue engineering.

A suitable degradation rate is pivotal to the success of corneal tissue engineering. Therefore, the degradation rates of microgrooved collagen films were evaluated with an in vitro degradation assay in collagenase solution, and Fig. 4c showed the relative residual mass of collagen films as a function of time. As we can see, although W100D50 and W50D50 showed slightly lower degradation rate than the other two films at the beginning stage, there was no significant difference in the average degradation rate of different collagen films, and almost all of the collagen films were degraded completely in $14 \mathrm{~h}$. The results indicated that micropatterned collagen films possessed the
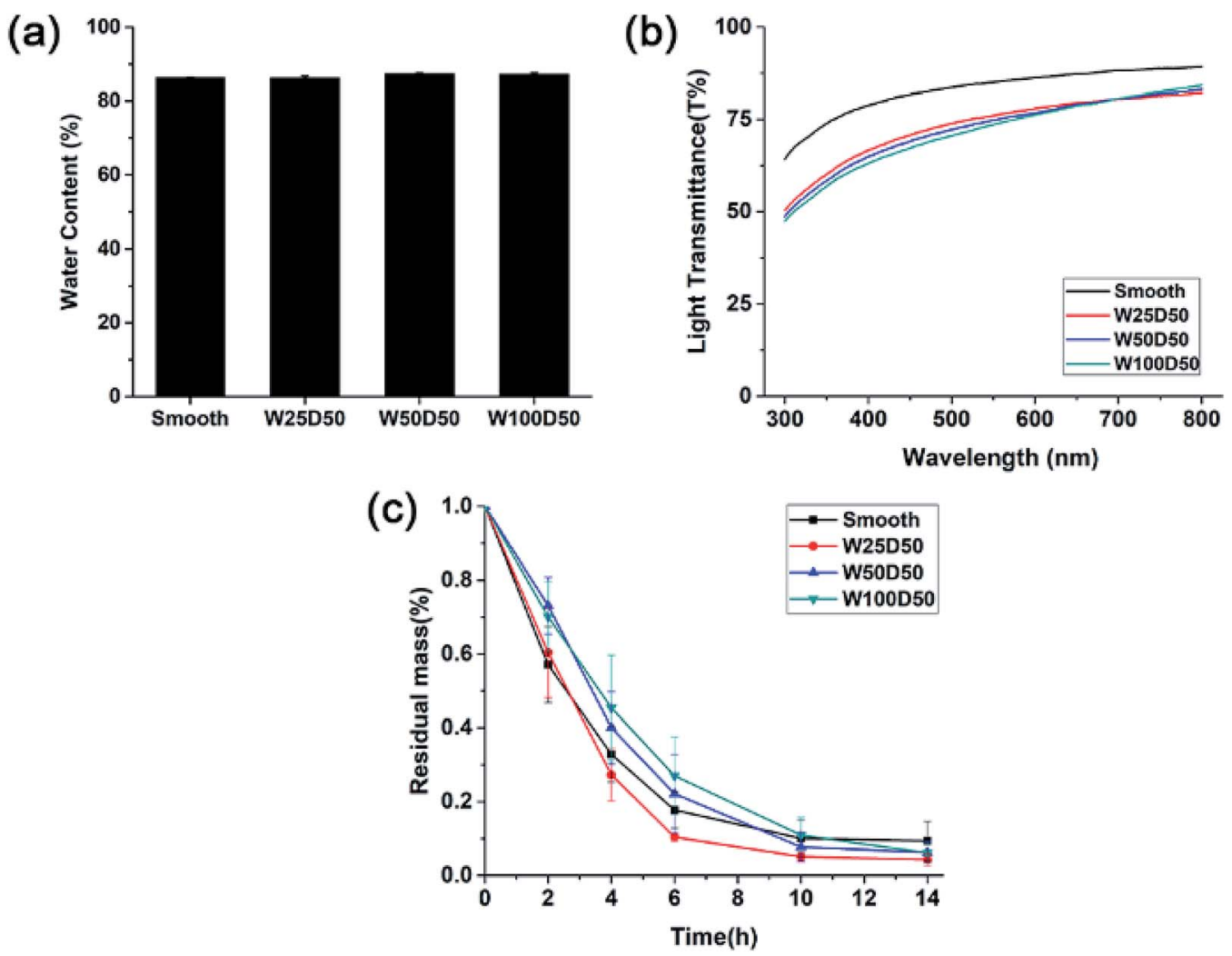

Fig. 4 (a) Equilibrium water absorption, (b) visible light transmission and (c) in vitro biodegradation rate in collagenase solution of collagen films. 
similar degradation rate with unpatterned films and the process of surface patterning had no significant influence on the degradation of collagen films. The reason might be that the process of surface micropatterning would not change the collagen internal microstructure and chemical activity.

\section{Cell orientation}

Although large quantities of studies have previously explored the influences of surface topography on corneal cell behaviour. $^{\mathbf{3 0 , 4 1 - 4 3}}$ Cell-topography interaction on patterned collagen films has not been revealed and exploited in corneal tissue engineering yet. In this paper, CECs and keratocytes were cultured on patterned collagen films and their responses were observed, hoping to reveal the effect of patterned surface on corneal cells and develop a tissue engineered cornea which has ability to inhibit corneal haze formation and accelerate epithelization.

Generally, one of the most noticeable impact of groove patterns on cells is that cells tend to elongate and align with the axis of the grooves, which is also described as contact guidance.
To determine cell orientation on the patterned collagen, CECs and keratocytes cultured on collagen films were stained by FActin Labelling Kit and DAPI after cultured for $48 \mathrm{~h}$ and then observed with a confocal laser scanning microscopy. The image captured were shown in Fig. 5a. As we can see, the population of CECs and keratocytes on patterned collagen films responded strongly and appeared marked alignment along the grooves. Whereas, on flat control, the cells showed a random arrangement. Besides, cells on the microgrooved sample was accompanied by an elongation of cell shape while the cells on planar films retained the original morphology. In order to show the alignment degree of cells intuitionally, the percentages of aligned cells were calculated, which was defined as alignment index. On patterned surface, a cell would be considered aligned with the grooves when the angle between the longest cell axis and the axis of grooves was less than $10^{\circ}$, or it would be considered randomly arranged. As we observed from the statistical results (Fig. $5 \mathrm{~b}$ and c), the alignment index was significantly increased from $20 \%$ on flat control to about $60 \%$ on patterned collagen film for both two types of cells. For (a)
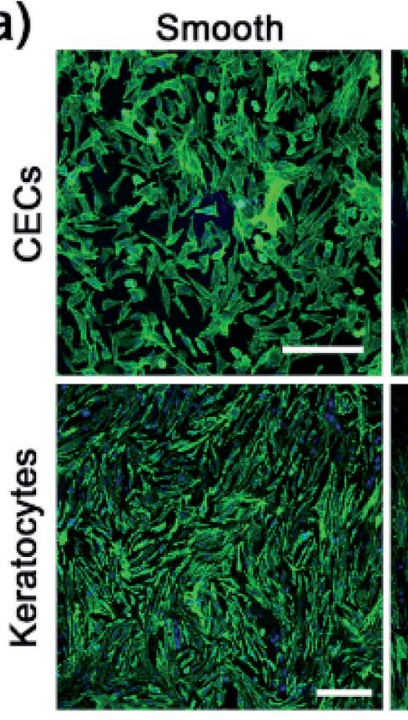
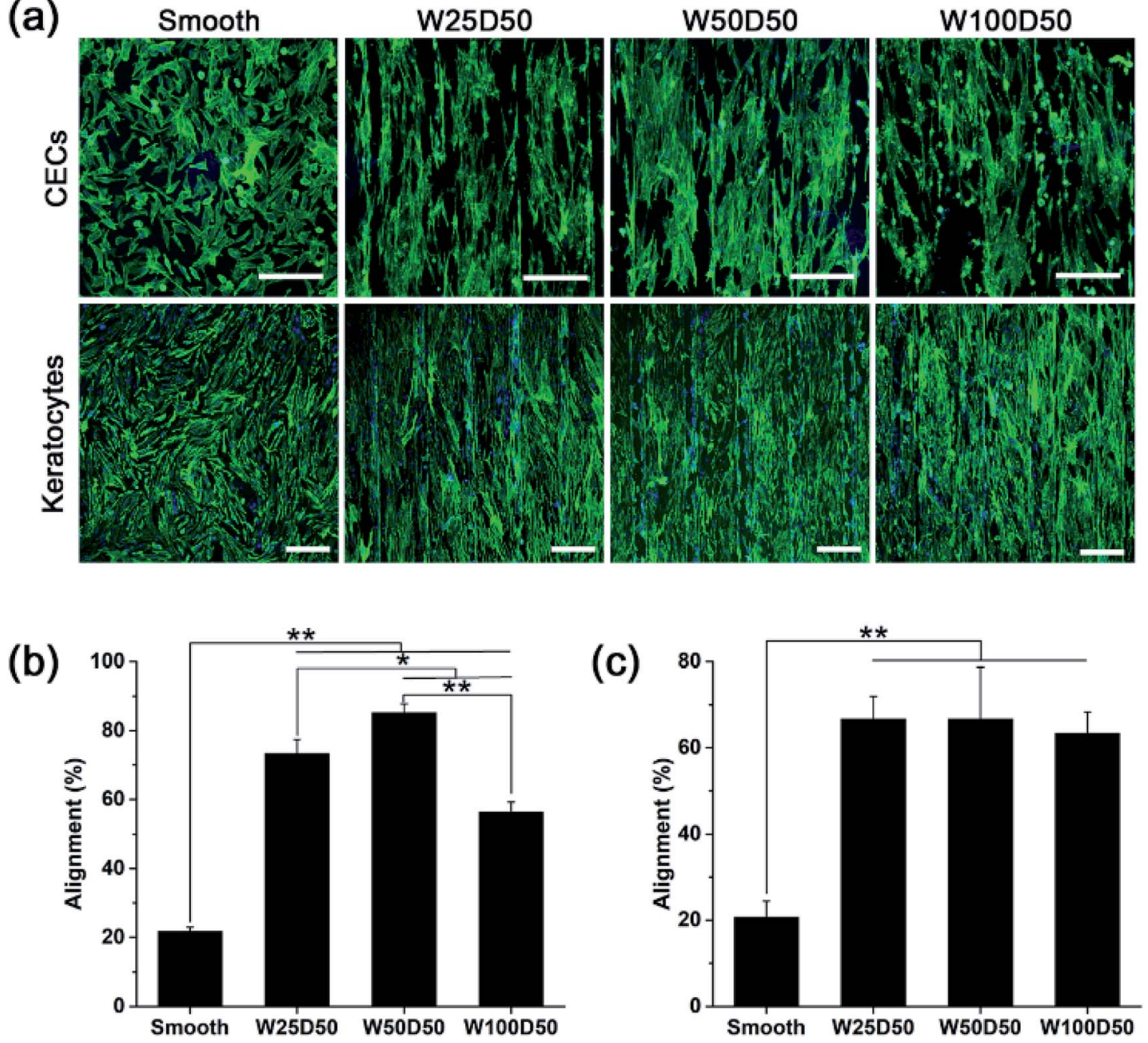

Fig. 5 Orientation of CECs and keratocytes cultured on collagen films. (a) Fluorescence image of CECs and keratocytes after 48 hours of culture on collagen films with F-actin and nucleus staining (scale bar $=250 \mu \mathrm{m}$ ). (b) Percentage of aligned CECs in total cell numbers (alignment index). (c) Percentage of aligned keratocytes in total cell numbers (alignment index). (*p<0.05,**p<0.01). 
keratocytes, there was no significant difference for different grooved films with different widths. However, the alignment index of CECs remained about 56\% on W100D50 but increased to $73 \%$ and $85 \%$ on W25D50 and W50D50, respectively.

Despite that cell responses to linear groove pattern depends on many factors, including cell types, feature sizes and physicochemical properties of substrate, the guidance of cell elongation and orientation occurred on numerous cell types seeded various substrates, except for some special cases. ${ }^{44}$ In addition, although the variation of feature size has shown ability to affect the degree of cell alignment, the effect is not universally observed in any circumstance. In present work, alignment of CECs was shown to be susceptible to groove width, and stronger alignment was observed on $50 \mu \mathrm{m}$-wide-grooves. In contrast, keratocytes didn't response to variations of groove width. The result demonstrated again that, for the same surface topography, different cell type would produce different response. In addition, Fraser et al. studied the response of CECs to submicron grooves and found that the alignment of CECs showed no difference on grooves with feature widths. ${ }^{45}$ These results suggested that CECs on grooves with submicro- or microscale sizes were regulated with different underlying mechanism. For keratocytes, studies of Teixeira et al. showed that percentage of aligned keratocytes remained $70 \%$ as the groove pitches increased from 800 to $4000 \mathrm{~nm},{ }^{42}$ which is constant with our results, indicating that grooves width varying in range of $800 \mathrm{~nm}$ to $100 \mu \mathrm{m}$ didn't have significant influence on degree of cell orientation.

\section{Cell proliferation}

As the main component of the cornea stroma, collagen has a good biocompatibility and is beneficial to cell proliferation. The patterned surface on the collagen films may also affect expansion of cells cultured on it, which might be the key factor to corneal tissue engineering. To quantitate the effects of designed groove patterns on proliferation of CECs and keratocytes, cells were seeded on collagen films and then tested by CCK-8 at 1, 3, 5 d. It could be seen from Fig. 6 that both CECs and keratocytes showed normal exponential growth on all collagen films. For CECs, there was no significant difference between cell proliferation rate on patterned collagen films and planar control for the first three days. However, cells on patterned films appeared a little slower proliferation rate than those on planar control at $5 \mathrm{~d}$, especially on W100D50 and W50D50. For keratocytes, cells on patterned collagen films tended to grow more slowly than those on planar control at beginning. Then, cells on W100D50 showed a distinctly lower proliferation rate compared with those on other films, and W50D50 and W25D50 are slightly more suitable for cell proliferation than planar films, but there was no difference between the two kind of grooved films and the smooth control.

Most reports showed that groove patterns usually result in lower proliferation than flat surface. ${ }^{\mathbf{4 6 , 4 7}}$ The CECs cultured on the collagen films in present work also showed the same trend. Currently, the mechanism of surface topography affecting cell proliferation has not been elucidated yet. However, cell shape has been repeatedly found to influence cell behaviours and control cell life and death. ${ }^{25,48}$ Thus, it can be hypothesized that surface topography regulates cell proliferation via changing cell shape. For CECs in present work, it is worth notice that the decrease of proliferation rate on patterned collagen films was accompanied by lager number of aligned cells. The restriction to cell spreading and marked change of cell shape might mainly account for the slower proliferation of CECs on microgrooves. For keratocytes, the morphology differences between cells on grooved surface and planar surface were relatively inapparent, and the aligned collective keratocytes was an imitation to highly-organized structure in native stromal tissue. These reasons could explain slightly promotion of proliferation rate of keratocytes on W50D50 and W25D50 but decrease of keratocyte proliferation on W100D50, suggesting that more than one mechanism was involved in cell proliferation on microgrooves with different feature size. The decreased proliferation on W100D50 might be related with the restricted cell spreading on microgrooves. When cultured on narrower grooves, such as W25D50 and W50D50, cells could bridge across the grooves. ${ }^{49}$ Whereas, grooves of W100D50 are too wide to bridge for keratocytes, which restricted cell spreading and resulted in decrease on cell proliferation. Thus, these results also indicated that different types of cells may have different responses to the same topological microstructure.
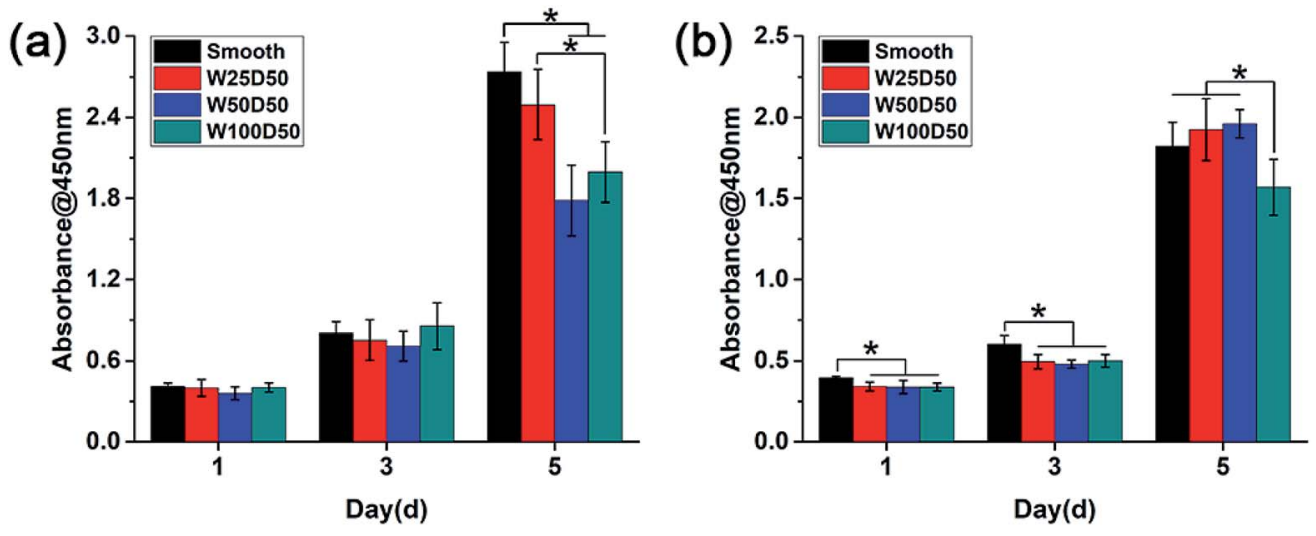

Fig. 6 Cell proliferation behaviour measured by CCK-8 assay after culturing (a) CECs and (b) keratocytes on collagen films. 


\section{Cell migration and healing}

It has been found that the migration phase, where cells around the wound migrate to cover the bare part, plays an important role in corneal epithelial wound healing. ${ }^{50,51}$ Therefore, rapid migration of CECs may accelerate wound healing on corneal epithelium. Previous researches have demonstrated that cell migration on grooved surface would be restricted along the axis of grooves. ${ }^{52,53}$ In present study, an in vitro wound healing assay was designed to investigate the contact guidance to CECs of patterned films and the effect of surface pattern on the speed of wound healing. Before CECs were seeded onto the films, a titanium strip was placed onto each film perpendicular to the grooves. After $24 \mathrm{~h}$ of culture, titanium strips were removed, and distinct wounds with a width of $1 \mathrm{~mm}$ were attained. Then the wound healing process was observed. As Fig. 7 shows, compared to the flat control, wound healing process on patterned collagen films were significantly accelerated. After wound healing for $48 \mathrm{~h}$, there was still a gap on the smooth collagen films, but the wound on collagen films with patterned surface had disappeared completely. Among three kinds of patterned collagen films, faster wound healing was seen on narrower grooves. Previous study of Li et al. has shown similar results. ${ }^{54}$ From the fluorescent images, we could clearly see that the wound borders on topography patterns had become indistinctive since many cells have outpaced their partners and reached to centre at $48 \mathrm{~h}$. More accelerated cells on narrower grooves induced rapider cell migration, indicating the accelerated wound healing mainly owed to the speed-up of individual CECs along the grooves. In addition, the wound healing process is an outcome of cooperation of cell migration and cell proliferation. Therefore, the higher proliferation on W25D50 compared the other two patterned films might also contribute the fastest wound healing. Anyway, the guidance of groove patterns to cell migration indeed accelerated in vitro corneal epithelial wound healing, demonstrating its great potential in corneal epithelium reconstruction and regeneration.

\section{Cell differentiation}

It has been repeated shown that topography is a powerful tool to control cell differentiation, including osteogenic differentiation, ${ }^{55}$ cardiac differentiation, ${ }^{56}$ and neuronal differentiation, ${ }^{57}$ indicating the possibility of regulating keratocyte differentiation with surface topography. Stromal wound healing process has been shown to depend on a complex cascade of many factors. ${ }^{51,58}$ In some abnormal healing process, a stromal fibrosis, also named corneal haze, forms and leads to vision impairment. According to previous reports, the light scattering structure actually is composed of myofibroblasts and disorganized extracellular matrix produced by them. ${ }^{13,59,60}$ In normal corneal stromal tissue, keratocytes are relatively quiescent, and aligned collagen fibrils are arranged packed in stacked collagen lamellae to form a highly-organized structure which has lower light scattering. ${ }^{61-63}$ After stroma injured, keratocytes would transform into more activated fibroblasts and further

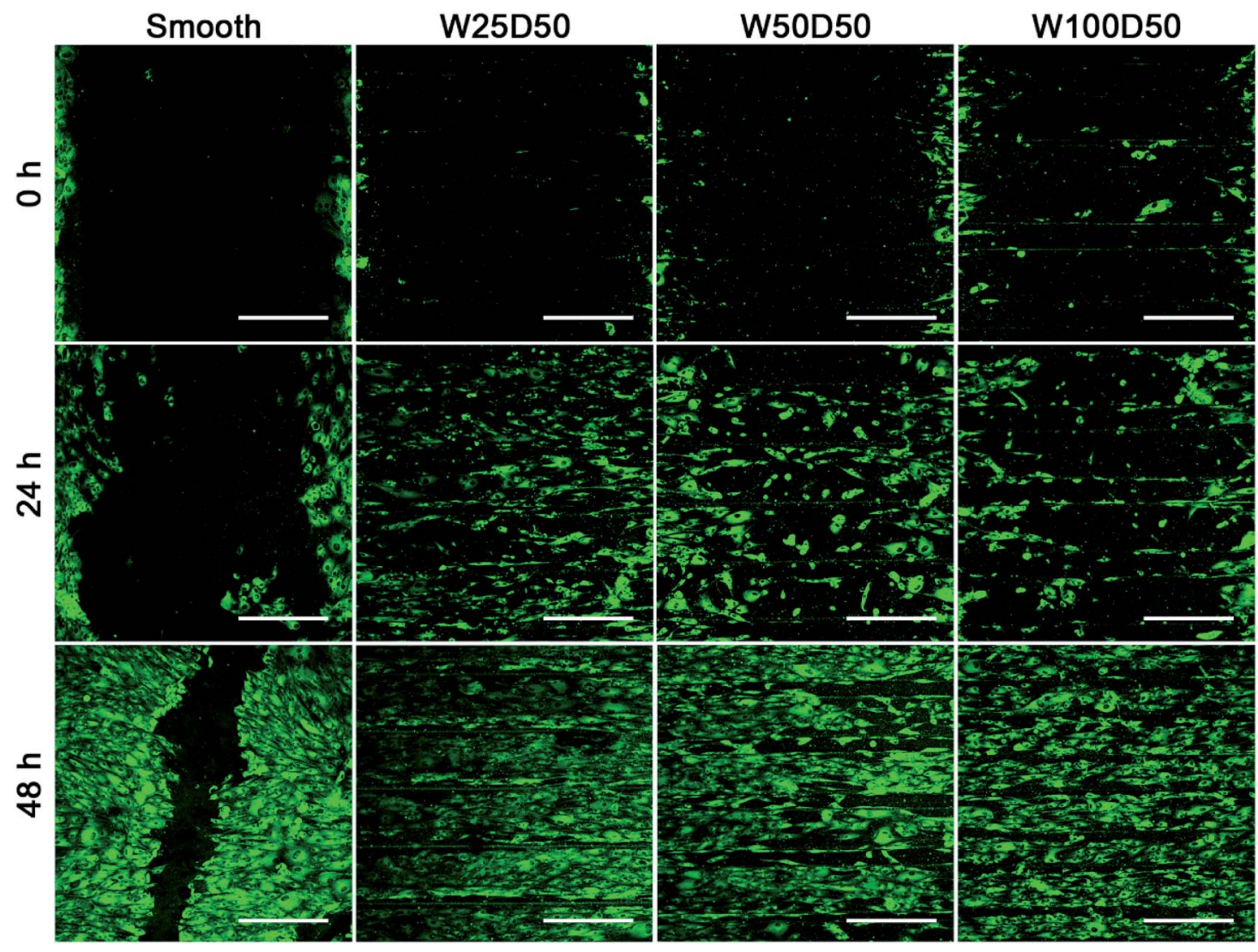

Fig. 7 The fluorescent images of in vitro corneal epithelial wound gap on collagen films at 0, 24, $48 \mathrm{~h}$. (scale bar $=400 \mu \mathrm{m}$ ). 
(a)

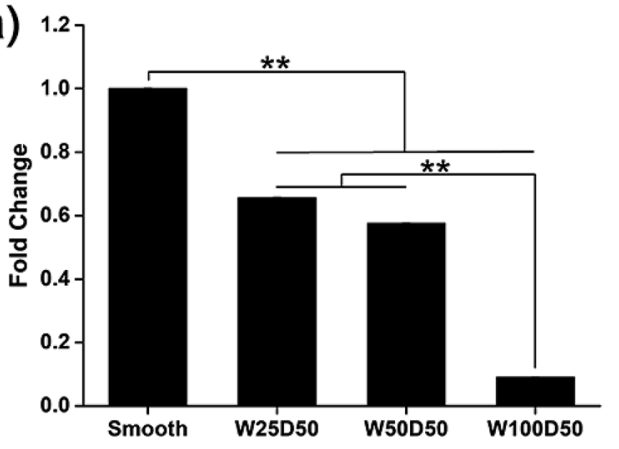

(b)

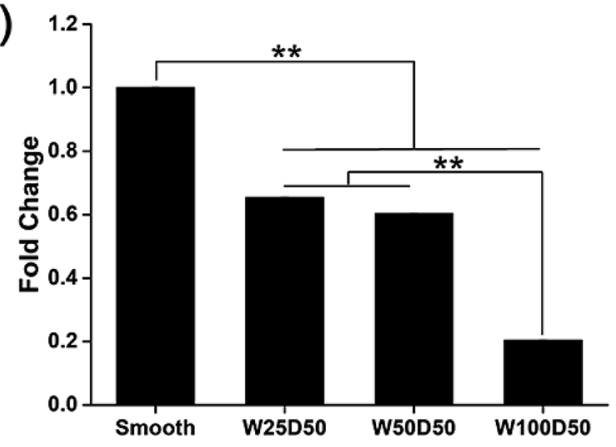

(c)

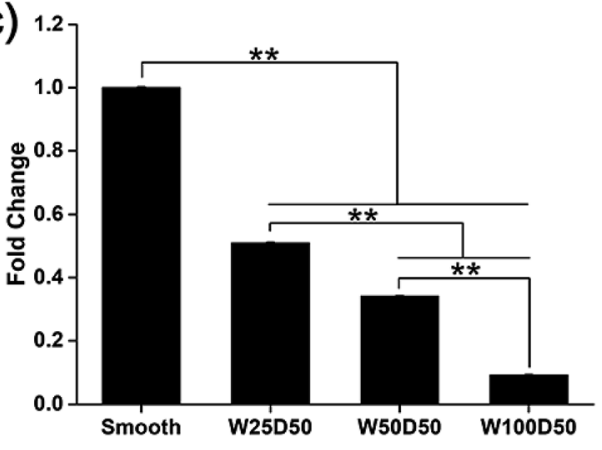

Fig. 8 mRNA expression level of (a) CTGF, (b) COL1A1, and (c) aSMA in keratocytes on collagen films. $(* p<0.05, * * p<0.01)$.

differentiate into myofibroblasts at the presence of transforming growth factor $\beta$ (TCF- $\beta$ ), which finally results in the formation of stromal haze. Myofibroblasts are characterized by their unique expression level of alpha smooth muscle actin ( $\alpha \mathrm{SMA})$. Connective tissue growth factor (CTGF) is a peptide that stimulates collagen (COLA1A) and $\alpha$ SMA synthesis of myofibroblast and proliferation of fibroblasts. ${ }^{64-66}$

To evaluate the influence of underlying microgrooves on the keratocyte-myofibroblast transformation, mRNA expression level of CTGF, COL1A1, and aSMA in keratocytes on microgrooved collagen films were determined by RT-PCR. Results was (a)

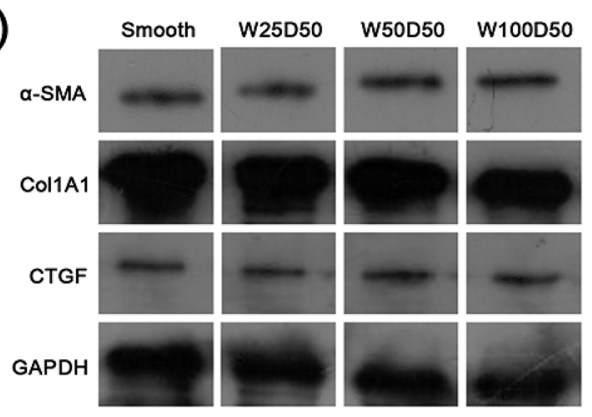

(c)

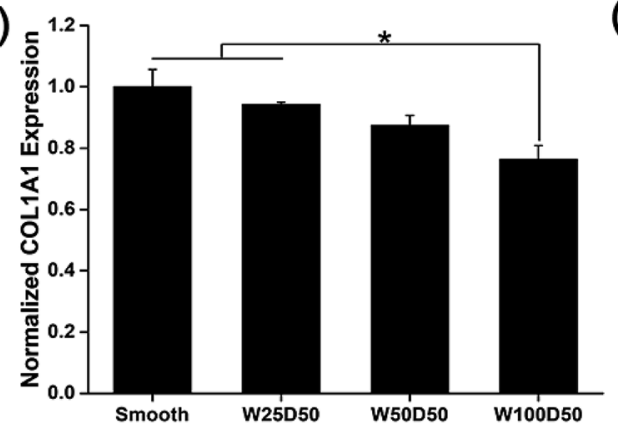

(b)

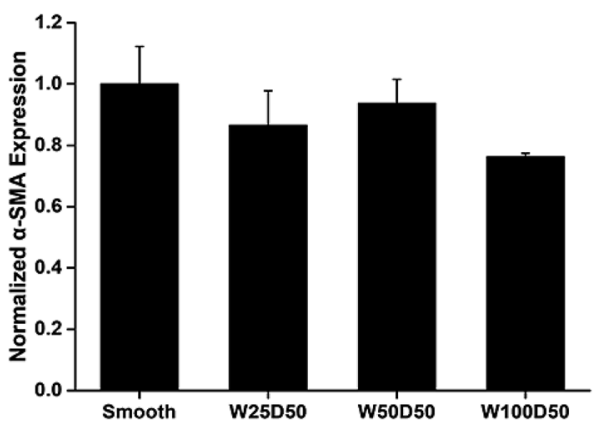

(d)

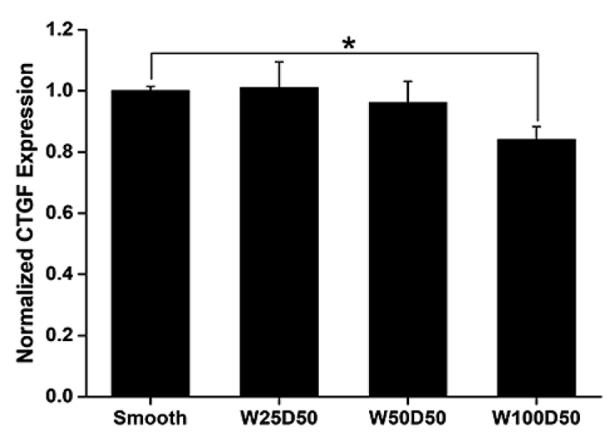

Fig. 9 Expression level of marker proteins of keratocytes induced by TGF- $\beta$ on collagen films detected by western blot, protein imprinting bands (GAPDH as reference protein) (a), the expression level of $\alpha$-SMA (b), COL1A1 (c) and CTGF (d). $(* p<0.05, * * p<0.01)$. 
shown on Fig. 8. Compared to planar collagen films, patterned collagen films induced significantly downregulated expression level of CTGF, $\alpha \mathrm{SMA}$, and COL1A1 genes. Besides, the attenuation to the expression of the three genes became more profound corresponding to the increase of groove width. Fig. 9 was result of western blotting analysis. It was shown that keratocytes on patterned collagen films tended to express less CTGF, aSMA, and COL1A1, although the difference was not as significant as the difference of gene expression level. The lower aSMA expression indicated that the differentiation of keratocytes into myofibroblasts were inhibited, which may mainly account for the decreased gene expression of CTGF and COL1A1. However, another explanation could be that activities of myofibroblasts was hampered by the surface topography. A study of Myrna et al. showed that nanoscale grooves help to stabilize the fibroblast phenotype compared to flat control, ${ }^{67}$ and our study performed on microscale grooves showed the same trend. These results suggested that keratocytes transformation are susceptible to topographic feature, and the topographic cues on native corneal stroma may also be involved in the maintenance of quiescent keratocytes. Therefore, the topography feature can be used to prevent the formation of corneal fibrosis.

\section{Conclusions}

In this paper, the microgrooved collagen films with different features were fabricated as a corneal tissue engineering scaffold to determine the effect of topography on physiochemical properties of collagen films and corneal cell behaviors. It was found that micropatterned collagen films possessed the good swelling performance, optical performance and biodegradability comparable with human cornea and can meet the needs of corneal repair. Besides, in vitro cell experiment demonstrated that topographic cues on collagen films can regulate the fundamental cell behaviors of CECs and keratocytes, including orientation, proliferation, migration and gene expression. CECs and keratocytes on patterned films showed significantly cell alignment and the alignment index is more than $55 \%$. The acceleration of epithelial wound healing and inhibited keratocyte-myofibroblast transformation on patterned collagen films indicates the great potential of surface topography on corneal regeneration and reconstruction.

\section{Conflicts of interest}

There are no conflicts to declare.

\section{Acknowledgements}

This work was supported by the National Key Research and Development Program of China (grant number 2017YFC1105004), the National Natural Science Foundation of China (grant numbers 51603074, 31971261), the Natural Science Foundation of Guangdong Province (grant number 2017A030313294), the Guangdong Scientific and Technological Project (grant numbers 2014B090907004, 2015B08020123) and
Medical Scientific Research Foundation of Guangdong Province (grant number A2018169).

\section{References}

1 M. J. Burton, Community Eye Health, 2009, 22, 33.

2 I. L. Tsai, C. C. Hsu, K. H. Hung, C. W. Chang and Y. H. Cheng, J. Chin. Med. Assoc., 2015, 78, 212-217.

3 P. Garg, P. V. Krishna, A. Stratis and U. Gopinathan, Eye, 2005, 19, 1106-1114.

4 C. E. Ghezzi, J. Rnjak-Kovacina and D. L. Kaplan, Tissue Eng. B Rev., 2015, 21, 278-287.

5 A. Shah, J. Brugnano, S. Sun, A. Vase and E. Orwin, Pediatr. Res., 2008, 63, 535-544.

6 Y. H. Huang, F. W. Tseng, W. H. Chang, I. C. Peng, D. J. Hsieh, S. W. Wu and M. L. Yeh, Acta Biomater., 2017, 58, 238-243.

7 X. Che, H. Wu, C. K. Jia, H. M. Sun, S. K. Ou, J. Q. Wang, M. V. Jeyalatha, X. He, J. W. Yu, C. Y. Zuo, Z. G. Liu and W. Li, Invest. Ophthalmol. Visual Sci., 2019, 60, 517-527.

8 J. E. Song, B. R. Sim, Y. S. Jeon, H. S. Kim, E. Y. Shin, C. Carlomagno and G. Khang, J. Biomater. Sci. Polym. Ed., 2019, 30, 263-275.

9 H. Kim, J. Jang, J. Park, K. P. Lee, S. Lee, D. M. Lee, K. H. Kim, H. K. Kim and D. W. Cho, Biofabrication, 2019, 11, 9.

10 R. N. Palchesko, S. D. Carrasquilla and A. W. Feinberg, Adv. Healthc. Mater., 2018, 7, 18.

11 Z. Chen, J. J. You, X. Liu, S. Cooper, C. Hodge, G. Sutton, J. M. Crook and G. G. Wallace, Biomed. Mater., 2018, 13, 27. 12 X. Duan and H. Sheardown, Biomaterials, 2006, 27, 46084617.

13 A. A. M. Torricelli, A. Santhanam, J. H. Wu, V. Singh and S. E. Wilson, Exp. Eye Res., 2016, 142, 110-118.

14 C. J. Dong and Y. G. Lv, Polymers, 2016, 8, 20.

15 G. A. Abrams, E. Bentley, P. F. Nealey and C. J. Murphy, Cells Tissues Organs, 2002, 170, 251-257.

16 G. A. Abrams, S. S. Schaus, S. L. Goodman, P. F. Nealey and C. J. Murphy, Cornea, 2000, 19, 57-64.

17 G. A. Abrams, S. L. Goodman, P. F. Nealey, M. Franco and C. J. Murphy, Cell Tissue Res., 2000, 299, 39-46.

18 K. M. Meek and C. Boote, Exp. Eye Res., 2004, 78, 503-512.

19 J. Huang, T. Tu, W. B. Wang, Z. Gao, G. D. Zhou, W. J. Zhang, X. L. Wu and W. Liu, J. Biomed. Mater. Res., Part A, 2019, 107, 1366-1378.

20 D. Ho, J. L. Zou, X. J. Chen, A. Munshi, N. M. Smith, V. Agarwal, S. I. Hodgetts, G. W. Plant, A. J. Bakker, A. R. Harvey, I. Luzinov and K. S. Iyer, ACS Nano, 2015, 9, 1767-1774.

21 C. H. Seo, K. Furukawa, K. Montagne, H. Jeong and T. Ushida, Biomaterials, 2011, 32, 9568-9575.

22 S. Nasrollahi, S. Banerjee, B. Qayum, P. Banerjee and A. Pathak, ACS Biomater. Sci. Eng., 2017, 3, 2980-2986.

23 S. Di Cio and J. E. Gautrot, Acta Biomater., 2016, 30, 26-48. 24 D. H. Kim, K. Han, K. Gupta, K. W. Kwon, K. Y. Suh and A. Levchenko, Biomaterials, 2009, 30, 5433-5444.

25 C. S. Chen, M. Mrksich, S. Huang, G. M. Whitesides and D. E. Ingber, Science, 1997, 276, 1425-1428. 
26 X. K. Shen, P. P. Ma, Y. Hu, G. Q. Xu, J. Zhou and K. Y. Cai, Colloids Surf., B, 2015, 127, 221-232.

27 H. C. Gao, X. D. Cao, H. Dong, X. L. Fu and Y. J. Wang, J. Mater. Sci. Technol., 2016, 32, 901-908.

28 M. J. Dalby, N. Gadegaard, R. Tare, A. Andar, M. O. Riehle, P. Herzyk, C. D. W. Wilkinson and R. O. C. Oreffo, Nat. Mater., 2007, 6, 997-1003.

29 B. B. Li, V. Agarwal, D. Ho, J. P. Vede and K. S. Iyer, New J. Chem., 2018, 42, 7237-7240.

30 A. I. Teixeira, G. A. McKie, J. D. Foley, P. J. Berticsc, P. F. Nealey and C. J. Murphy, Biomaterials, 2006, 27, 39453954.

31 A. I. Teixeira, G. A. Abrams, P. J. Bertics, C. J. Murphy and P. F. Nealey, J. Cell Sci., 2003, 116, 1881-1892.

32 S. A. Pot, S. J. Liliensiek, K. E. Myrna, E. Bentley, J. V. Jester, P. F. Nealey and C. J. Murphy, Invest. Ophthalmol. Visual Sci., 2010, 51, 1373-1381.

33 S. Koo, S. J. Ahn, H. Zhang, J. C. Wang and E. K. F. Yim, Cell. Mol. Bioeng., 2011, 4, 399-410.

34 M. D. M. Evans, G. A. McFarland, S. Taylor and X. F. Walboomers, Biomaterials, 2005, 26, 1703-1711.

35 B. Yanez-Soto, S. J. Liliensiek, J. Z. Gasiorowski, C. J. Murphy and P. F. Nealey, Biomaterials, 2013, 34, 9244-9251.

36 W. Zhang, J. L. Chen, L. J. Backman, A. D. Malm and P. Danielson, Adv. Healthc. Mater., 2017, 6, 11.

37 Q. Zhang, H. Dong, Y. L. Li, Y. Zhu, L. Zeng, H. C. Gao, B. Yuan, X. F. Chen and C. B. Mao, ACS Appl. Mater. Interfaces, 2015, 7, 23336-23345.

38 H. C. Gao, H. Dong, X. D. Cao, X. L. Fu, Y. Zhu, C. B. Mao and Y. J. Wang, Langmuir, 2015, 31, 6797-6806.

39 S. P. Srinivas, Optom. Vis. Sci., 2010, 87, E239-E254.

40 J. E. Harris and L. T. Nordquist, Am. J. Ophthalmol., 1955, 40, 100-110.

41 E. J. Tocce, V. K. Smirnov, D. S. Kibalov, S. J. Liliensiek, C. J. Murphy and P. F. Nealey, Biomaterials, 2010, 31, 40644072.

42 A. I. Teixeira, P. F. Nealey and C. J. Murphy, J. Biomed. Mater. Res., Part A, 2004, 71, 369-376.

43 S. J. Liliensiek, S. Campbell, P. F. Nealey and C. J. Murphy, J. Biomed. Mater. Res., Part A, 2006, 79, 185-192.

44 J. Meyle, K. Gultig and W. Nisch, J. Biomed. Mater. Res., 1995, 29, 81-88.

45 S. A. Fraser, Y. H. Ting, K. S. Mallon, A. E. Wendt, C. J. Murphy and P. F. Nealey, J. Biomed. Mater. Res., Part A, 2008, 86, 725-735.
46 C. J. Bettinger, Z. T. Zhang, S. Gerecht, J. T. Borenstein and R. Langer, Adv. Mater., 2008, 20, 99-103.

47 J. Lu, M. P. Rao, N. C. MacDonald, D. Khang and T. J. Webster, Acta Biomater., 2008, 4, 192-201.

48 X. Yao, R. Peng and J. Ding, Adv. Mater., 2013, 25, 5257-5286. 49 Q. Zhang, Y. L. Li, H. Sun, L. Zeng, X. Li, B. Yuan, C. Y. Ning,

H. Dong and X. F. Chen, RSC Adv., 2015, 5, 47975-47982.

50 L. Lu, P. S. Reinach and W. W. Y. Kao, Exp. Biol. Med., 2001, 226, 653-664.

51 A. V. Ljubimov and M. Saghizadeh, Prog. Retin. Eye Res., 2015, 49, 17-45.

52 S. A. Biela, Y. Su, J. P. Spatz and R. Kemkemer, Acta Biomater., 2009, 5, 2460-2466.

53 J. P. Kaiser, A. Reinmann and A. Bruinink, Biomaterials, 2006, 27, 5230-5241.

54 S. Li, S. Bhatia, Y. L. Hu, Y. T. Shin, Y. S. Li, S. Usami and S. Chien, Biorheology, 2001, 38, 101-108.

55 D. Karazisis, S. Petronis, H. Agheli, L. Emanuelsson, B. Norlindh, A. Johansson, L. Rasmusson, P. Thomsen and O. Omar, Acta Biomater., 2017, 53, 559-571.

56 L. D. Ghosh, A. Jain, N. R. Sundaresan and K. Chatterjee, Mater. Sci. Eng., C, 2018, 88, 104-114.

57 L. Q. Song, K. Wang, Y. Li and Y. Yang, Colloids Surf., B, 2016, 148, 49-58.

58 S. Saika, O. Yamanaka, Y. Okada and T. Sumioka, Exp. Eye Res., 2016, 142, 40-48.

59 T. Moller-Pedersen, Exp. Eye Res., 2004, 78, 553-560.

60 J. V. Jester, W. M. Petroll and H. D. Cavanagh, Prog. Retin. Eye Res., 1999, 18, 311-356.

61 J. R. Hassell and D. E. Birk, Exp. Eye Res., 2010, 91, 326-335.

62 L. J. Muller, E. Pels, L. Schurmans and G. Vrensen, Exp. Eye Res., 2004, 78, 493-501.

63 D. M. Maurice, J. Physiol., 1957, 136, 263-286.

64 A. Igarashi, H. Okochi, D. M. Bradham and G. R. Grotendorst, Mol. Biol. Cell, 1993, 4, 637-645.

65 K. Kikuchi, T. Kadono, H. Ihn, S. Sato, A. Igarashi, H. Nakagawa, K. Tamaki and K. Takehara, J. Invest. Dermatol., 1995, 105, 128-132.

66 G. R. Grotendorst and M. R. Duncan, FASEB J., 2005, 19, 729738.

67 K. E. Myrna, R. Mendonsa, P. Russell, S. A. Pot, S. J. Liliensiek, J. V. Jester, P. F. Nealey, D. Brown and C. J. Murphy, Invest. Ophthalmol. Visual Sci., 2012, 53, 811. 